\title{
Mössbauer spectroscopy—a useful method for classification of meteorites?
}

\author{
J. Galazka-Friedman ${ }^{1} \cdot$ M. Woźniak ${ }^{2} \cdot$ P. Duda ${ }^{1}$. \\ P. Rzepecka ${ }^{1}$ - M. Jakubowska ${ }^{1}$ - L. Karwowski ${ }^{3}$
}

Published online: 27 September 2017

(C) The Author(s) 2017. This article is an open access publication

\begin{abstract}
The aim of our studies was to check the usefulness of Mössbauer spectroscopy for preliminary classification of ordinary chondrites. Mössbauer spectra of 50 samples of ordinary chondrites (type LL, L and H) obtained at room temperature were analyzed. 35 Mössbauer spectra were obtained in our laboratory, the other spectra were taken from the literature. The conclusion of our study was, that the most useful way for the preliminary classification of the ordinary chondrites is the application of two types of plots based on the data obtained by Mössbauer spectroscopy. One type of these plots is a linear plot which was used for the identification of the samples which are unrepresentative. The second type of these plots is a plot of "spectral area of the olivine" vs "spectral area of the metallic phase". This last one was used for the identification of two unknown meteorites.
\end{abstract}

Keywords Mossbauer spectral area $\cdot$ Ordinary chondrites $\cdot$ Baszkowka $\cdot$ Classification of meteorites

\section{Introduction}

The majority of falling meteorites are fragments of rocks composed of silicate. They are called stony meteorites. Other types of meteorites called stony-iron and iron are much less

This article is part of the Topical Collection on Proceedings of the 3rd Mediterranean Conference on the Applications of the Mössbauer Effect (MECAME 2017), Jerusalem, Israel, 5-7 June 2017 Edited by Mira Ristic, Stjepko Krehula, Israel Nowik and Israel Felner

J. Galazka-Friedman jgfrie@if.pw.edu.pl

1 Faculty of Physics, Warsaw University of Technology, Koszykowa 75, 00-662 Warsaw, Poland

2 Faculty of Biology, University of Warsaw, Miecznikowa 1, 02-096, Warsaw, Poland

3 Faculty of Earth Sciences, University of Silesia, Sosnowiec, Poland 
frequent. Modern classification of meteorites is based on hypotheses about the way of formation and evolution of the parent body of the meteorite. Up to now 50000 meteorites were classified.

The most numerous group of meteorites falling on the Earth are ordinary chondrites (almost $77 \%$ of observed falls). They are divided into few types and sub-types taking into consideration the amount of metallic iron and composition of the silicate phase. In this paper we investigated equilibrated ordinary chondrites type $\mathrm{H}$ (high iron), L (low iron) and LL (low iron, low metal). They are composed of a silicate matrix (olivine and pyroxene) and grains of metallic iron and troilite. These grains are spread in the matrix. The other minerals are accessories.

The aim of our studies was to check the usefulness of Mössbauer spectroscopy for preliminary classification of ordinary chondrites.

The Mössbauer spectrum of the non-weathered equilibrated ordinary chondrites is composed of 4 subspectra: two doublets from olivines and pyroxenes and two sextets from metallic phases and troilite. When the process of weathering begins in the meteorite, a fifth subspectrum of trivalent iron appears.

The first suggestion of the application of Mössbauer spectroscopy to the classification of stony meteorites was made by Herr and Skerra [1] in 1969. It was strictly connected with the classical method of classification of meteorites and was based on the precise determination (from the Mössbauer spectra) of the concentration of the different mineralogical phases in various types of the meteorites. This idea was abandoned because of difficulties related to the determination of the amount of iron in the investigated samples.

In early 2000 a Mössbauer group from India started systematic studies on the possibility of the application of Mössbauer spectroscopy to the classification of ordinary chondrites [24]. Using different types of plots such as "areas for metallic phases vs. areas for nonmetallic phases", "areas for metallic phases vs. areas for silicate phases" and "areas for pyroxene vs. areas for olivine" this group determined regions for H, L and LL types of the meteorites. Using this method they were able to classify the meteorite Itawa-Bhopij fallen in India in 2000 as ordinary chondrite type L

The systematics of the Mössbauer absorption area was also applied for confirmation of the type of the ordinary chondrite Lynch 001 by a group from Australia [5]. This method was also applied by Maksimowa et al. [6] for ordinary chondrites measured with a high velocity resolution.

Our preliminary analyzes on the possibility of the application of Mössbauer spectroscopy to the simplified classification of the ordinary chondrites were presented in a paper published in 2014 [7].

\section{Material and method}

In this paper the analyzes of Mössbauer spectra of 50 samples of equilibrated ordinary chondrites type LL, L and $\mathrm{H}$ are presented. Only the results of the measurements of nonweathered meteorites (the amount of ferric iron less than 6\%) will be discussed. Mössbauer spectra of 35 meteorites were obtained in Warsaw. The others spectra are taken from the literature.

The samples of bulk meteorites were crushed and ground into fine powder in an agate mortar. After grinding, the samples were loaded into Mössbauer plastic holders. Mössbauer spectra of ${ }^{57} \mathrm{Fe}$ were measured at room temperature with a conventional Mössbauer spectrometer. A $15 \mathrm{mCi}^{57} \mathrm{Co}$-in-Rhodium source, giving an unsplit emission line, was used. The 

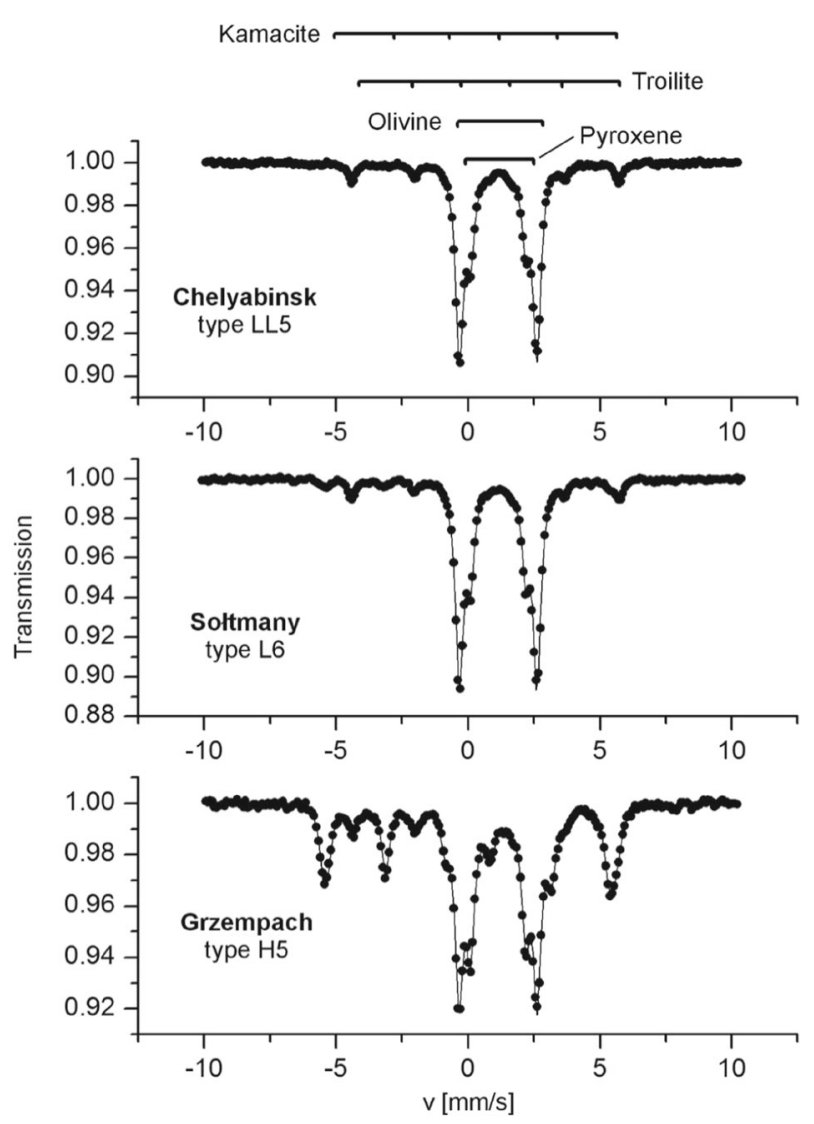

Fig. 1 Mössbauer spectra of 3 ordinary chondrites: : Chelyabinsk (type LL), Soltmany (type L) and Grzempach (type H) obtained at RT

$14.4 \mathrm{keV}$ gamma rays were detected by a proportional counter. The velocity scales were calibrated using an iron foil absorber at room temperature. The fitting procedure was performed using the "Full Static Hamiltonian" analysis in the Recoil program. As the troilite has an axial symmetry only theta angle was fitted.

\section{Results and discussion}

\subsection{Mössbauer spectra of ordinary chondrites type LL. L and H}

In Fig. 1 Mössbauer spectra of 3 typical ordinary chondrites: Chelyabinsk (type LL), Sołtmany (type L) and Grzempach (type H) are shown. All these spectra are composed of 4 subspectra: two doublets from olivines and pyroxenes and two sextets from metallic phases and troilite. These 4 mineral phases are the main components of non-weathered, ordinary chondrites type LL, L and $\mathrm{H}$. The subspectra of ferric iron were also fitted. It is easy to notice that the increasing spectral area from kamacite is the main feature of these spectra. 


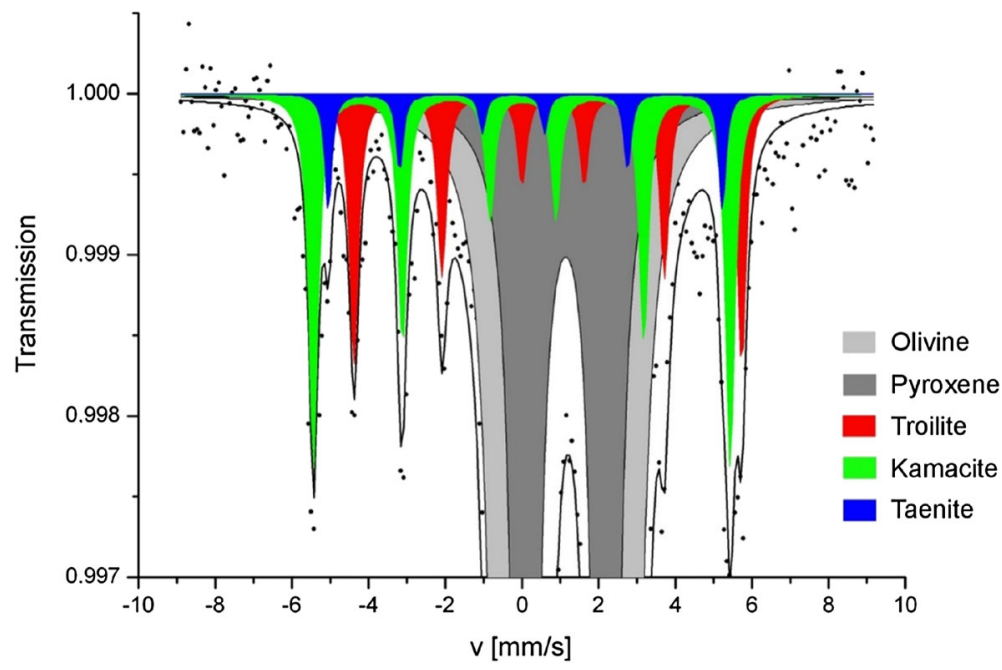

Fig. 2 Mössbauer spectrum of magnetic phases isolated from the Sołtmany meteorite

Table 1 Mössbauer parameters obtained from the best fit to the experimental spectrum of magnetic phase isolated from the Soltmany meteorite

\begin{tabular}{lllllll}
\hline Mineral phase & $\mathrm{IS}[\mathrm{mm} / \mathrm{s}]$ & $\mathrm{B}_{\mathrm{eff}}[\mathrm{T}]$ & $\mathrm{e}^{2} \mathrm{qQ} / 2[\mathrm{~mm} / \mathrm{s}]$ & $\Theta\left[{ }^{\circ}\right]$ & $\mathrm{w}[\mathrm{mm} / \mathrm{s}]$ & $\mathrm{A}[\%]$ \\
\hline Olivine & $1.14(2)$ & 0 & $2.94(2)$ & - & $0.17(2)$ & $56(1)$ \\
Pyroxene & $1.14(2)$ & 0 & $2.10(2)$ & - & $0.16(2)$ & $32(1)$ \\
Kamacite & 0.02 & $33.8(2)$ & $0.05(2)$ & - & $0.14(2)$ & $6(1)$ \\
Taenite & $0.07(2)$ & $32.1(2)$ & $0.20(2)$ & - & $0.10(2)$ & $2(1)$ \\
Troilite & $0.74(2)$ & $31.1(1)$ & $0.73(2)$ & $64(1)$ & $0.13(2)$ & $4(1)$ \\
\hline
\end{tabular}

IS isomer shift, B internal magnetic field, $\mathrm{e}^{2} \mathrm{qQ} / 2$ quadrupole interaction parameter, w HWHM (half width at half maximum), $\Theta$ angle between direction of magnetic field and the main axis of the electric field gradient, A spectral area

\subsection{Metallic phase}

In Grzempach's spectrum the sextet with the highest value of the magnetic field was fitted by two sextets: one from kamacite (spectral area $=12 \%$ ) and another one from taenite $($ spectral area $=17 \%)$.

In the sample of meteorite Soltmany investigated by us, probably taenite is also present, but its identification without separation of magnetic and non-magnetic phase was very difficult.

In Fig. 2 the Mössbauer spectrum of a sample of meteorite Soltmany, which was obtained as a result of magnetic separation, is shown. In this sample not only the kamacite's sextet is visible, but identification of the taenite's sextet is also possible. In Table 1 Mössbauer parameters obtained from the best fit to the spectrum of metallic phase isolated from Soltmany meteorite are shown.

In our paper, according to the suggestion of Verma et al. [3] spectral area of kamacite and taenite are called "spectral area of metallic phase". 
Table 2 The range of the values of spectral areas from different mineralogical phase present in ordinary chondrites type $\mathrm{H}$

\begin{tabular}{lllll}
\hline & Olivine [\%] & Pyroxene [\%] & Metallic phase [\%] & Troilite [\%] \\
\hline Our own data $(\mathrm{n}=6)$ & $47-29$ & $25-21$ & $29-11$ & $20-13$ \\
Data from literature $(\mathrm{n}=10)$ & $47-33$ & $33-18$ & $29-9$ & $23-12$ \\
\hline
\end{tabular}

$\mathrm{n}$-number of analyzed meteoritic samples

Table 3 The range of values of the spectral areas from different mineralogical phase present in ordinary chondrites type L

\begin{tabular}{lllll}
\hline & Olivine [\%] & Pyroxene [\%] & Metallic phase [\%] & Troilite [\%] \\
\hline Our own data $(\mathrm{n}=13)$ & $65-41$ & $26-19$ & $16-3$ & $22-10$ \\
Data from literature $(\mathrm{n}=2)$ & $60-49$ & $24-19$ & $10-9$ & $16-11$ \\
\hline
\end{tabular}

$\mathrm{n}$-number of analyzed meteoritic samples

\subsection{Spectral areas of olivine, pyroxene, metallic phase and troilite present in ordinary chondrites type $H, L$ and $L L$}

Values of spectral areas from olivine, pyroxene, metallic phase and troilite were calculated for following 6 ordinary chondrites type H: Pultusk, Grzempach, Kidairat, Carancas, Juancheng and Tandakht. Similar values were taken from the literature for 10 following meteorites: Allegan [4], Didwana [4], Gujargaon [4], Kosice [8], Ochansk [9], Richardton [9], Torino [10], Vengerovo [9], Xingyang [11], Zvonkov [9]. The range of these values are shown in Table 2.

Values of spectral areas from olivine, pyroxene, metallic phase and troilite were calculated for following 13 ordinary chondrites type L: Barwell, Colby, Farmington, Mount Tanzerzait, Ohuma, Shisr 176, Soltmany, Elenovka, Katol, Battle Mountain. Similar values were taken from the literature for two following meteorites: Kunashak [9] and New Halfa [12]. The range of these values are shown in Table 3.

Values of spectral areas from olivine, pyroxene, metallic phase and troilite were calculated for following 10 samples of ordinary chondrites type LL: Chelyabinsk1, Chelyabinsk2, Bjurböle1, Bjurböle2, NWA 7313, NWA 8602, NWA 7733, NWA 8590, Benguerir, Oued el Hadjar. Similar values were taken from the literature for 3 following meteorites: Bandog [4], Bhawad [4], Tuxtuac [4]. The range of these values are shown in Table 4.

Lack of metallic phase in the data taken from the literature is the most important difference between our own data and those taken from the literature.

In Table 5 values of spectra areas obtained for 4 different samples of Baszkówka meteorite are presented. The sum of these values is not always equal $100 \%$ because in investigated samples of Baszkówka meteorite the fifth subspectrum of trivalent iron was present.

\subsection{Application of linear plot for identification of unrepresentative samples}

Occurrence of unrepresentative samples of meteorites is a real problem in our studies. One of the causes of this may be related to intentional or unintentional choice of samples with 
Table 4 The range of the values of spectral areas from different mineralogical phase present in ordinary chondrites type LL

\begin{tabular}{lllll}
\hline & Olivine [\%] & Pyroxene [\%] & Metallic phase [\%] & Troilite [\%] \\
\hline Our own data $(\mathrm{n}=10)$ & $65-51$ & $29-18$ & $5.8-0.3$ & $17-5$ \\
Data from literature $(\mathrm{n}=3)$ & $64-61$ & $29-21$ & $0-0$ & $15-10$ \\
\hline
\end{tabular}

$\mathrm{n}$-number of analyzed meteoritic samples

Table 5 Values of spectral areas for 4 different samples of Baszkówka meteorite

\begin{tabular}{lllll}
\hline Baszkówka samples & Olivine [\%] & Pyroxene [\%] & Metallic phase [\%] & Troilite [\%] \\
\hline Baszkówka B1 & 33 & 16 & 23 & 25 \\
Baszkówka B2 & 35 & 21 & 14 & 28 \\
Baszkówka B3 & 28 & 24 & 13 & 33 \\
Baszkówka B4 & 26 & 18 & 29 & 26 \\
\hline
\end{tabular}

a preference to one of the mineralogical phase. If the analyzed Mössbauer spectrum has $\mathrm{n}$ phases, then the construction of the plot: sum $(\mathrm{n}-1)$ of phases vs the phase nth should be a straight lane with the slope equal -1 . Samples containing surplus of nth phase (positioned on the axis " $x$ ") should escape from the set of correctly prepared samples along line with slope -1 to the direction of increasing values of " $x$ ". Based on the collected data 4 types of the linear plots were constructed. These are: plot(ol+pyr+met) vs (tr) (Fig. 3), plot $(\mathrm{ol}+$ pyr+tr) vs (met) (Fig. 4), plot(pyr+met+tr) vs (ol) (Fig. 5) and plot(ol+met+tr) vs (pyr) (Fig. 6). They form a straight line. On these plots the points corresponding to 4 samples of the meteorite Baszkówka (which was classified as ordinary chondrites type L ) were marked by the yellow color.

It has to be noticed that some experimental points are below the straight line. It is caused by the presence of a small subspectrum of trivalent iron being the result of weathering.

At the plot (ol+pyr+met) vs tr four pointes (yellow color) belonging to 4 samples of Baszkówka meteorite (L4) are outside of the region occupied by ordinary chondrites type L. They are also outside of the region occupied by ordinary chondrites type $\mathrm{H}$. This observation is in favor of the suggestion that samples of Baszkówka meteorite were chosen with the intention to have higher concentration of troilite. This confirms the hypothesis that these samples of Baszkówka meteorite are not-representative for the whole meteorite and should be eliminated from the reference base of the standard meteorites.

In Fig. 4 two samples of Baszkówka meteorite are at the end of the region occupied by samples of the meteorites type $\mathrm{H}$. This observation also support the hypothesis that these samples of Baszkówka meteorite are not-representative for the whole meteorite body.

At the plot (pyr+met+tr) vs ol one point belonging to ordinary chondrite type L (red color) is outside the region occupied even by ordinary chondrite type LL. This point represents a sample of the meteorite Shirs 176. The representability of this sample should also be checked.

In Fig. 6 regions occupied by different types of the meteorites are mixed up. This means that the amount of iron in pyroxenes does not depend on the type of the meteorite. 


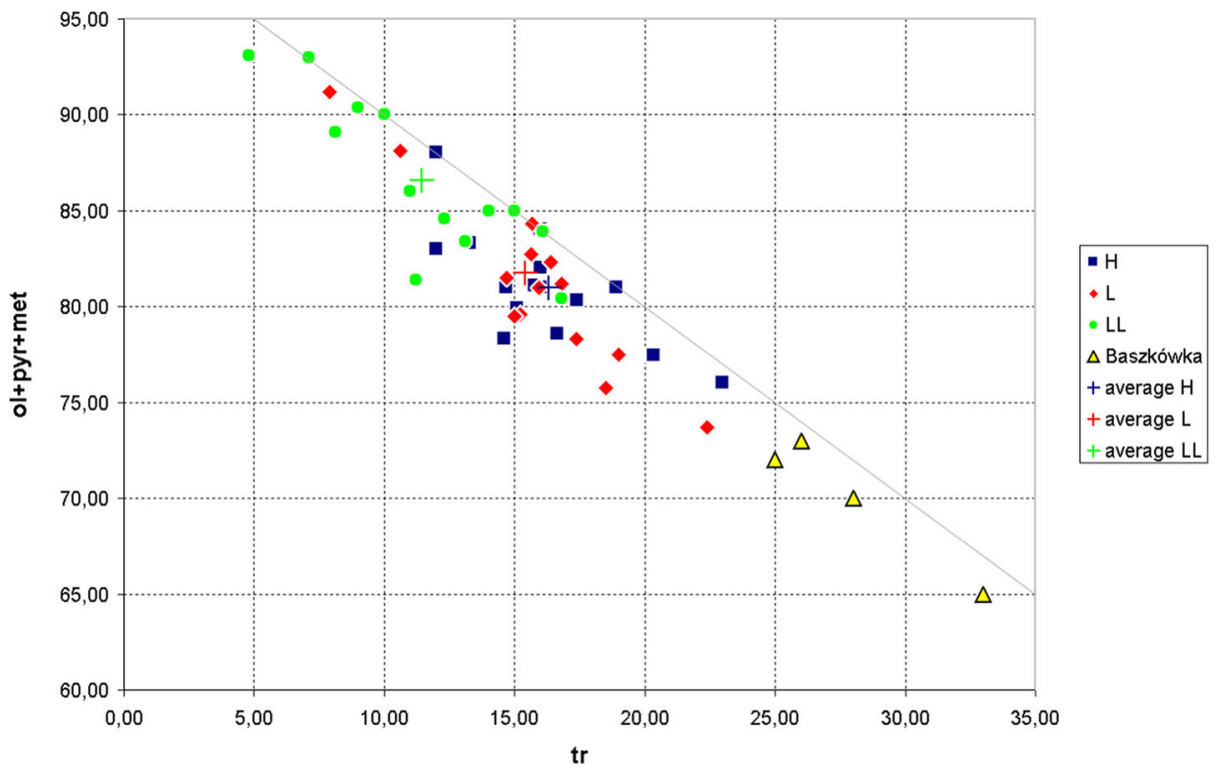

Fig. 3 Plot of the sum of spectral areas of 3 mineralogical phases (olivine, pyroxene, metallic phase) vs spectral area of troilite for ordinary chondrites type H, L, LL and 4 samples of Baszkówka meteorite classified as ordinary chondrite type L. On the line of the slope -1 there are 10 points which represent non-weathered meteorites with the spectral area of ferric iron equal zero. The points below the line have the spectral area of ferric iron higher than zero

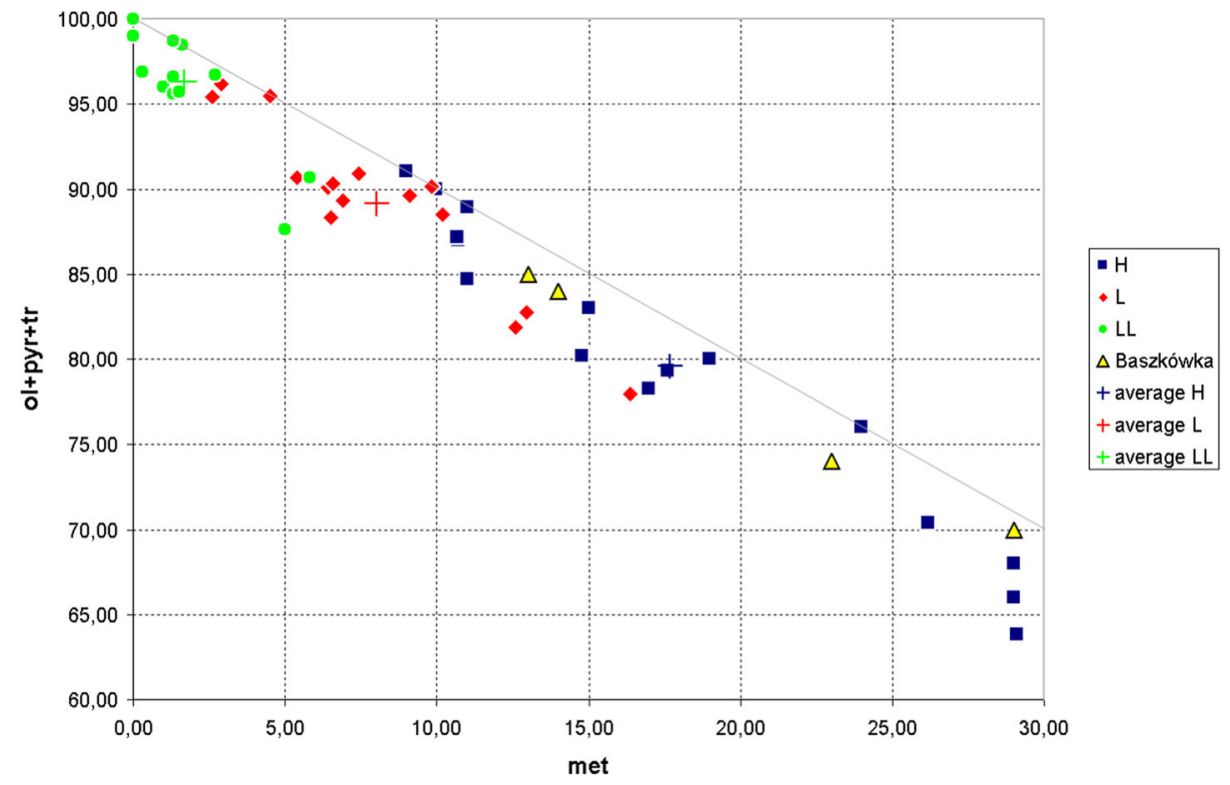

Fig. 4 Plot of the sum of spectral areas of 3 mineralogical phases (olivine, pyroxene, troilite) vs spectral area of metallic phase for ordinary chondrites type H, L, LL and 4 samples of Baszkówka meteorite classified as ordinary chondrite type L. On the line of the slope -1 there are 10 points which represent non-weathered meteorites with the spectral area of ferric iron equal zero. The points below the line have the spectral area of ferric iron higher than zero 


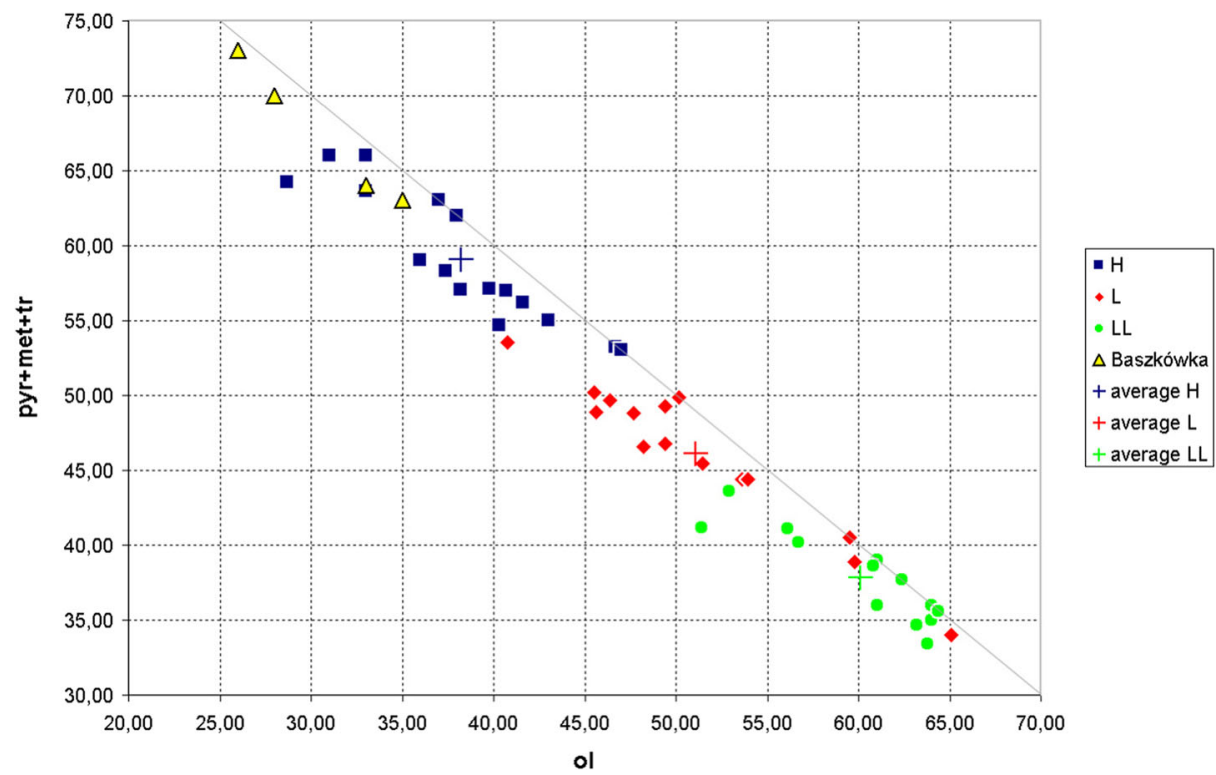

Fig. 5 Plot of the sum of spectral areas of 3 mineralogical phases ( pyroxene, metallic phase troilite) vs spectral area of olivine for ordinary chondrites type H, L, LL and 4 samples of Baszkówka meteorite classified as ordinary chondrite type L. On the line of the slope -1 there are 10 points which represent non-weathered meteorites with the spectral area of ferric iron equal zero. The points below the line have the spectral area of ferric iron higher than zero

\subsection{Two examples of the application of the plot "spectral areas of the olivine vs. spectral areas of the metallic phase" for determination of the type of the samples of "unknown ordinary chondrites"}

Figure 7 is a plot of spectral areas of olivine vs spectral areas of metallic phase for 44 samples of known meteorites and 2 samples from unknown meteorites $(u(1)$ and $u(2))$ which had to be identified based on their positions on the plot. Mean values (MV) and population variances (PVR) for the ordinary chondrites type H, L and LL were calculated and marked on the plot by crosses. The lengths of the branches of the crosses are equal to the values of population variance.

The analysis of the parameters of the position of unknown sample $u(2)$ leads to unequivocal conclusion that it is a sample of ordinary chondrite type $\mathrm{H}$. As this chondrite was a sample of ordinary chondrite Cosina (H4), the identification by our method was confirmed as fully correct.

The position of the sample $\mathrm{u}(1)$ at the plot does not allow unequivocal identification as this samples is located at the border of the area occupied by ordinary chondrites $\mathrm{H}$ and $\mathrm{L}$. We were informed that the samples was from Pervomaisky meteorite - ordinary chondrite type L. Its location at the plot may point to an excess of metallic phase. It may be due to the fact that the sample was taken from the part of the meteorite which was close to the fusion crust area of the meteorite (see Fig. 8) 


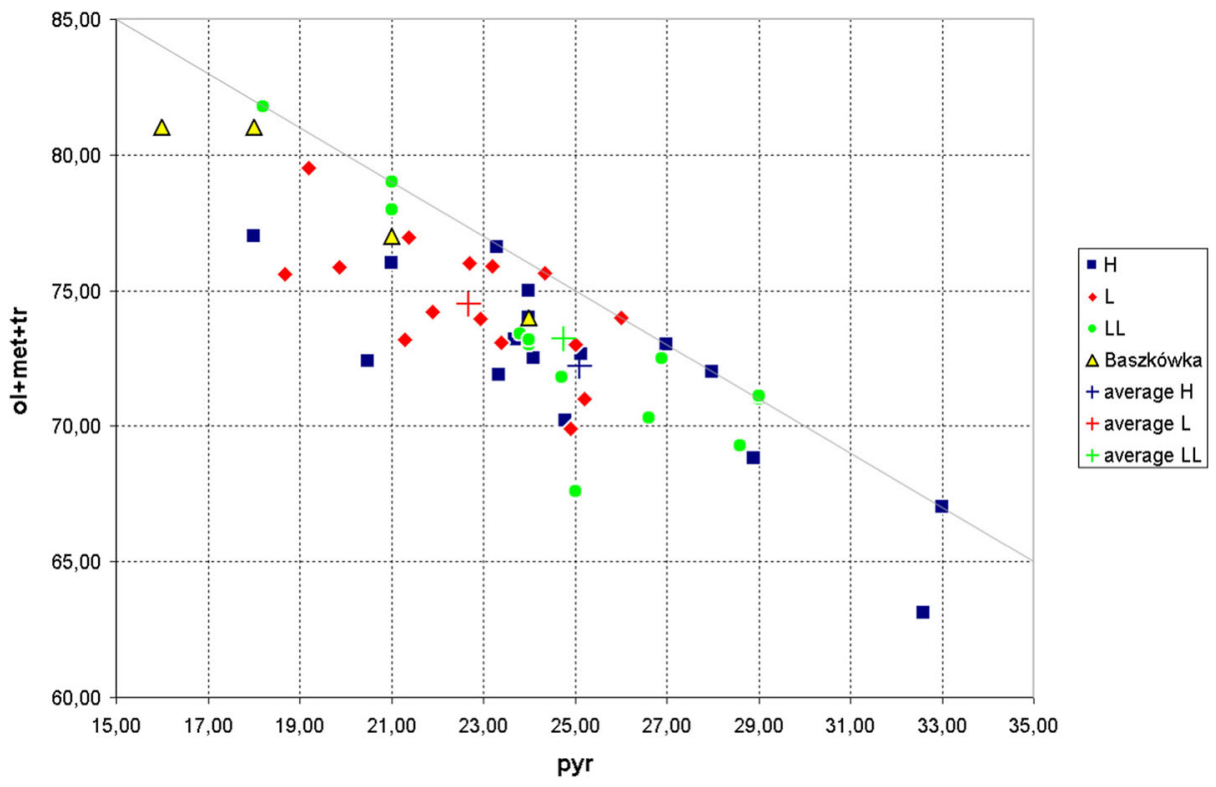

Fig. 6 Plot of the sum of spectral areas of 3 mineralogical phases (olivine, metallic phase,troilite) vs spectral area of pyroxene for ordinary chondrites type H, L, LL and 4 samples of Baszkówka meteorite classified as ordinary chondrite type L. On the line of the slope -1 there are 10 points which represent non-weathered meteorites with the spectral area of ferric iron equal zero. The points below the line have the spectral area of ferric iron higher than zero

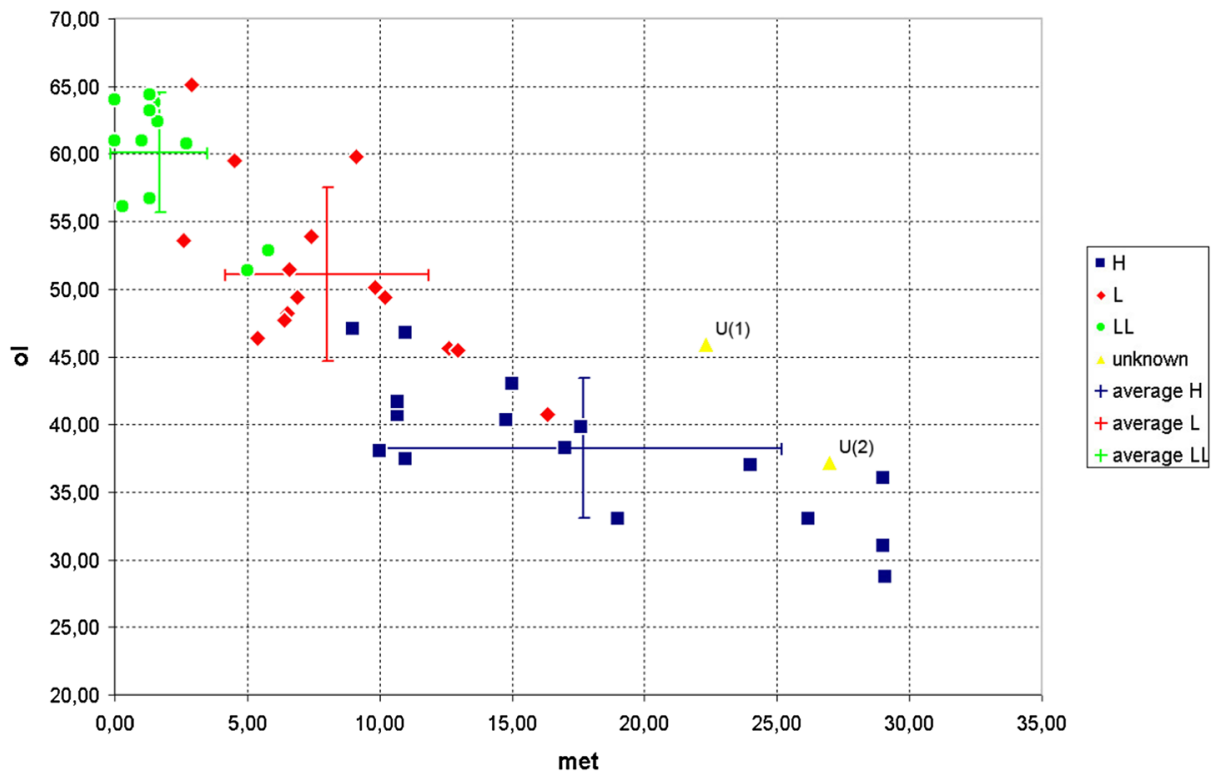

Fig. 7 Plot ol vs met for 44 samples of known meteorites ( 39 of them are falls, 5 are founds with very limited weathering - spectral area of ferric iron $<5 \%$ ) and 2 samples of unknown ones 


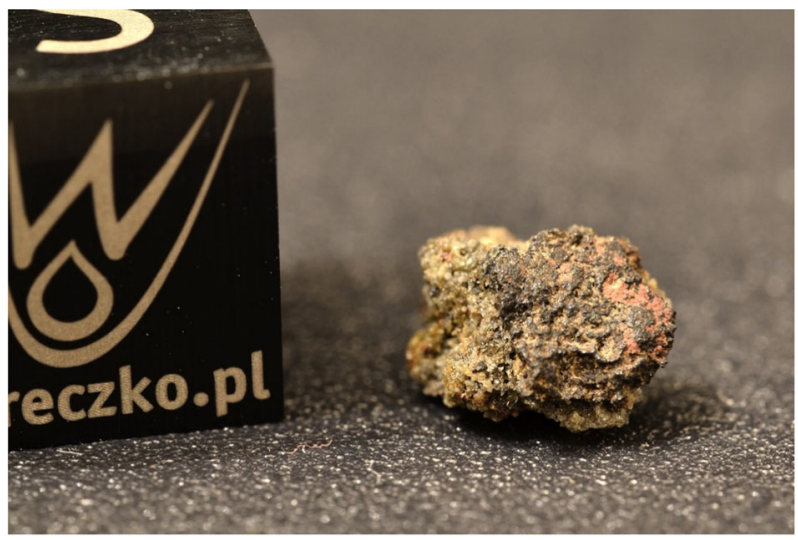

Fig. 8 A sample of Pervomaisky meteorite with a fragment of the fusion crust

Table 6 Mean values (MV) and population variance (PVAR) of spectral areas of different mineral phases (met, ol, pyr, tr) calculated for different types of ordinary chondrites

\begin{tabular}{|c|c|c|c|c|c|c|c|c|}
\hline \multirow{2}{*}{$\begin{array}{l}\text { Type of ordinary } \\
\text { Chondrites }\end{array}$} & \multicolumn{2}{|c|}{ Olivine } & \multicolumn{2}{|c|}{ Pyroxene } & \multicolumn{2}{|c|}{ Metallic phase } & \multicolumn{2}{|c|}{ Troilite } \\
\hline & MV & PVAR & MV & PVAR & MV & PVAR & MV & PVAR \\
\hline LL (13) & 60.1 & 4.4 & 24.8 & 3.3 & 1.7 & 1.8 & 11.4 & 3.6 \\
\hline $\mathrm{L}(15)$ & 51.1 & 6.4 & 22.6 & 2.8 & 8.0 & 3.9 & 15.4 & 3.7 \\
\hline H (16) & 38.2 & 5.2 & 25.1 & 4.0 & 17.7 & 7.5 & 16.3 & 2.9 \\
\hline
\end{tabular}

\subsection{Distribution of iron among different mineralogical phases in three types of ordinary chondrites}

In the Table 6 the average values of the spectral areas of different mineralogical phases: olivines, pyroxenes, metallic phase and troilite are shown. It should be noticed that in the Table 6 the results for equilibrated ordinary chondrites are shown. The composition for the un-equilibrated ordinary chondrites is different [13].

Analyzing this table we can note that with increasing value of the concentration of the total iron in meteorites type $\mathrm{LL}, \mathrm{L}$ and $\mathrm{H}$ :

a) the average value of the spectral area of metallic phase increases

b) the average value of the spectral area of olivine decreases

c) the average value of the spectral area of pyroxene is constant

d) the average value of the spectral area of troilite increases slightly

Two first observations ( $a$ and $b$ ) correlate well with the results obtained with the use of other methods. The same level of iron in pyroxenes (about 25\%) present in 3 types (LL, $\mathrm{L}$ and $\mathrm{H}$ ) of ordinary chondrites obtained from the Mössbauer measurements is difficult to explain at this stage of our investigation. 


\section{Conclusions}

It seems that Mössbauer spectroscopy is a very useful technique for investigating and classifying meteorites. Its big advantage is the small amount of material necessary for measurements. On the other hand this advantage may also be a misleading as the meteoritic sample measured may be unrepresentative of the whole meteorite. Thus the plot type $(\mathrm{ol}+\mathrm{pyr}+\mathrm{met}) \mathrm{vs} \operatorname{tr}$ (and other similar plots) suggested by us may identify unrepresentative samples.

The plot ol vs met is the most appropriate plot for the identification of unknown samples of the meteorites.

Acknowledgments Sue Forder took part in the initial phase of this investigation-thank you Sue.

The samples of meteorites for this study were generously supplied by Marcin Cimała, Ansgar Greshake, Mike Gilmer, Tomasz Jakubowski, Kazimierz Mazurek, Jarosław Morys, Krzysztof Socha, Robert Verish, Łukasz Karwowski and Jan Woreczko.

Open Access This article is distributed under the terms of the Creative Commons Attribution 4.0 International License (http://creativecommons.org/licenses/by/4.0/), which permits unrestricted use, distribution, and reproduction in any medium, provided you give appropriate credit to the original author(s) and the source, provide a link to the Creative Commons license, and indicate if changes were made.

\section{References}

1. Herr, W., Skerra, B.: Mössbauer spectroscopy applied to the classification of stone meteorites. In: Millman, P.M. (ed.) Meteorite Research. Astrophysics and Space Series. Science Library, vol. 12, pp. 106-122. D. Reidel Pub. Co, Dordrecht (1969)

2. Paliwal, B.S., Tripathi, R.P., Verma, H.C., Sharma, S.K.: Classification of the Didwana-Rajod meteorite: a Mössbauer spectroscopic study. Meteorit. Planet. Sci. 35, 639-642 (2000)

3. Verma, H.C., Rawat, A., Paliwal, B.S., Tripathi, R.P.: Mössbauer spectroscopic studies of an oxidized ordinary chondrite fallen at Itawa-Bhopji, India. Hyperfine Interact. 142, 643-652 (2002)

4. Verma, H.C., Jee, K., Tripathi, R.P.: Systematics of Mössbauer absorption areas in ordinary chondrites and applications to a newly fallen meteorite in Jodhpur, India. Meteorit. Planet. Sci. 38, 963-967 (2003)

5. Elewa, N.N., Cadogan, J.M.: An ${ }^{57}$ Fe Mössbauer study of the ordinary chondrite meteorite Lynch 001. Hyperfine Interact. 238, 4 (2017)

6. Maksimova, A.A., Oshtrakh, M.I., Petrova, E.V., Grokhovsky, V.I., Semionkin, V.A.: Comparison of iron-bearing minerals in ordinary chondrites from H, L and LL groups using Mössbauer spectroscopy with a high velocity resolution. Spectrochim. Acta A Mol. Biomol. Spectrosc. 172, 65-76 (2017)

7. Gałȧzka-Friedman, J., Szlachta, K., Karwowski, Ł.., Woźniak, M.: Mössbauer studies of Soltmany and Shisr 176 meteorites - comparison with other ordinary chondrites. Hyperfine Interact. 226, 593-600 (2014)

8. Lipka, J., Sitek, J., Dekan, J., Degmová, J., Porubčan, V.: Mössbauer study of Slovak meteorites. Hyperfine Interact. 218, 107-111 (2013)

9. Oshtrakh, M.I., Petrova, E.V., Grokhovsky, V.I., Semionkin, V.A.: A study of ordinary chondrites by Mössbauer spectroscopy with high velocity resolution. Meteorit. Planet. Sci. 43, 941-958 (2008)

10. Ortalli, I., Pedrazzi, G.: Study of the Torino meteorite. Hyperfine Interact. 57, 2275-2278 (1990)

11. Zhang, Y., Stevens, J.G., Li, Y., Li, Z.: Mössbauer study of the Jilin and Xinyang meteorites. Hyperfine Interact. 91, 547-550 (1994)

12. Abdu, Y.A., Ericsson, T.: Mössbauer spectroscopy, X-ray diffrac-tion, and electron microprobe analysis of the New Halfa meteorite. Meteorit. Planet. Sci. 32, 373-375 (1997)

13. Menzies, O.N., Bland, P.A., Berry, F.J., Cressey, G.: A Mössbauer spectroscopy and X-ray diffraction study of ordinary chondrites: quantification of modal mineralogy and implications for redox conditions during metamorphism. Meteorit. Planet. Sci. 40, 1023-1042 (2005) 